\title{
Expanding opportunities to publish in American Association for Thoracic Surgery journals
}

\author{
Richard D. Weisel, MD, ${ }^{\mathrm{a}}$ and Spencer McGrath, BA, MA ${ }^{\mathrm{b}}$
}

Last September, the editors of The Journal of Thoracic and Cardiovascular Surgery (JTCVS) shared several new developments under way with the American Association for Thoracic Surgery (AATS) publications, ${ }^{1}$ including the launch of 2 new open access journals: JTCVS Open and JTCVS Techniques. The new journals from the AATS provide additional options to publish high-quality information of importance to thoracic and cardiovascular surgeons. Authors who have submitted to JTCVS are offered transfer to one of our sister journals if their article has insufficient priority for publication in JTCVS.

We established this article transfer model more than 5 years ago when we began offering authors the option of publication in Seminars in Thoracic and Cardiovascular Surgery (Seminars). The option of transferring JTCVS submissions to Seminars has been extremely successful. In 2019, the articles of 86 authors were offered transfer to Seminars and 78 authors agreed to publish their article in Seminars, representing more than $90 \%$ author approval. The transferred articles are improved by the extensive revisions required by the JTCVS reviewers and JTCVS and Seminars editors. The transferred articles are also reviewed by the JTCVS statistical reviewers and editors so that the conclusions are justified by the results presented. The authors have revised their articles to the Journal's rigorous standards before publication. Each of these Seminars articles has the same standards of visual display and conclusive analytics required for the JTCVS.

In the past 5 years, there has been a progressive increase in readership and citations to Seminars as our community has embraced the value offered. Seminars articles are now highly downloaded and frequently cited in articles published in other high-impact journals. As a result, Seminars will now become indexed in the Science Citation Index Expanded and will be awarded an Impact Factor in June 2020! On the basis of the citation rate in 2018, we calculated a projected Impact Factor of 1.6, and we are expecting Seminars to debut a similar Impact Factor later this year. Please join us in congratulating the

\footnotetext{
From ${ }^{a}$ Toronto General Hospital, Toronto, Ontario, Canada; and ${ }^{\mathrm{b}}$ American Association for Thoracic Surgery, Beverly, Mass.

Disclosures: Authors have nothing to disclose with regard to commercial support.

Address for reprints: Richard D. Weisel, MD, Toronto General Hospital, 101 College

St, TMDT 3-704, Toronto, Ontario M5G 1L7, Canada (E-mail: Richard.weisel@ uhn.ca).

J Thorac Cardiovasc Surg 2020;159:1169-70

$0022-5223 / \$ 36.00$

Copyright (c) 2020 by The American Association for Thoracic Surgery

https://doi.org/10.1016/j.jtcvs.2020.02.047
}

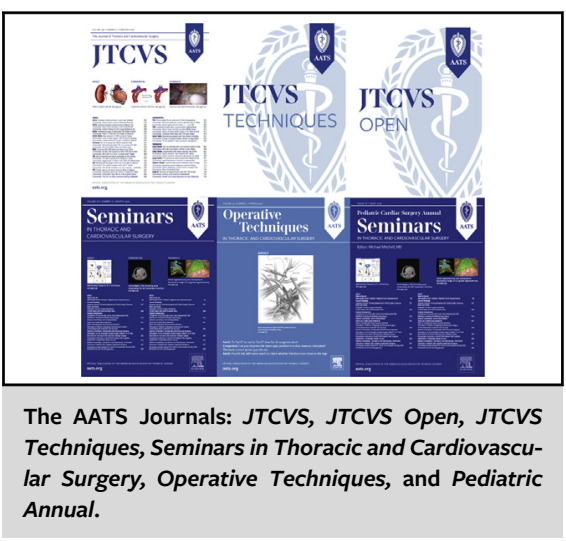

\begin{abstract}
CENTRAL MESSAGE
An expanded portfolio of AATS publications, including 2 new open access journals, JTCVS Open and JTCVS Techniques, provides additional opportunities to publish an increasing number of high-quality articles. Each article receives a full review by JTCVS and is modified to meet our exacting standards before transfer to one of the new journals. As a result, we anticipate our community will appreciate the quality and value of the articles published in the 2 new journals.
\end{abstract}

editors of JTCVS and Seminars on achieving this prestigious milestone!

The editors have now expanded this model to JTCVS Open and JTCVS Techniques, and we expect similar success over the next 3 to 5 years with both JTCVS Open and JTCVS Techniques. Each article receives a full review by JTCVS and is modified to meet our exacting standards before transfer to one of the new journals. As a result, we anticipate our community will appreciate the quality and value of the articles published in the 2 new journals. With the increasing impact factor of the JTCVS, we have seen a progressive 


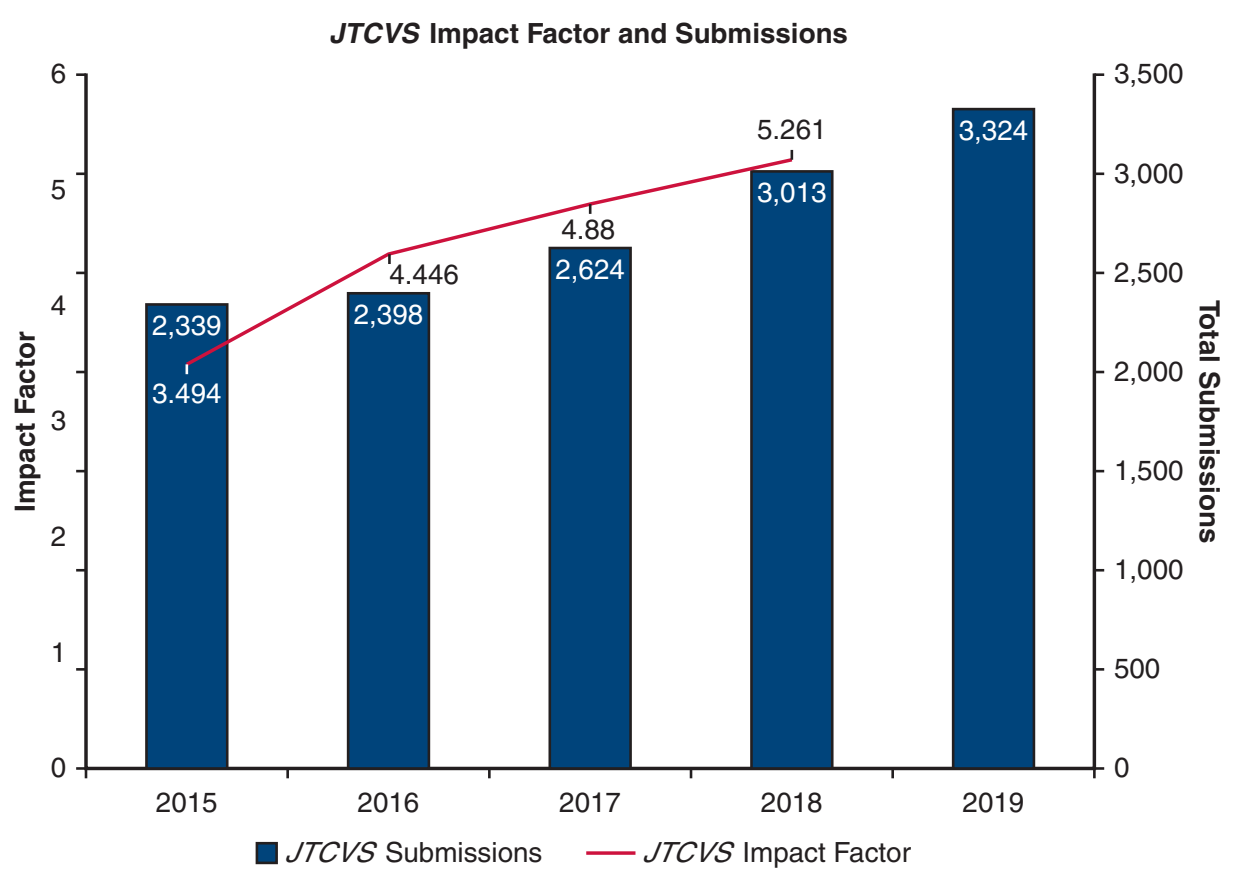

FIGURE 1. Submissions to JTCVS 2015 to 2019 and the JTCVS Impact Factor 2015 to 2018. JTCVS, The Journal of Thoracic and Cardiovascular Surgery.

increase in the number of manuscripts submitted (Figure 1). We anticipate that we will be able to facilitate the publication of an increasing number of high-quality articles in our new journals.

As with many new journals recently, JTCVS Open and JTCVS Techniques are open access, and authors are requested to pay an article processing charge for publication after an article has been accepted. The advantage of the open access model is that all articles are immediately available to all readers worldwide without restrictions. In our initial experience with the new journals, authors have responded positively and agreed to transfer articles. As of January 2020, JTCVS Open has 5 articles in press and JTCVS Techniques has more than 30 Brief Reports in various stages of publication. The early success of these journals will facilitate a timely application to PubMed. Our aim is for both journals to be indexed in PubMed in the next 12 months, at which time PubMed will index all articles retroactively to the first article.

Readers of JTCVS will notice many of the valuable aspects of JTCVS carried over to JTCVS Open and JTCVS Techniques. Each article transferred to JTCVS Open or JTCVS Techniques is published with at least 1 Commentary from an expert in the field. In addition, leading experts have contributed articles originally presented at the AATS 99th Annual Meeting in Toronto, which will be published early in 2020, and we plan to receive more contributions from the 100th Annual Meeting in New York. We want our readers to discover this important information published across all AATS journals with as few barriers as possible. Readers of JTCVS will be given single-click, immediate access to all the high-quality articles published in JTCVS Open and JTCVS Techniques from the online version or print version (using the $\mathrm{QR}$ code) of the Journal-look for the "Recent Papers in AATS Journals" page published at the beginning of each subspecialty section of the Journal. Also, we have begun to provide readers access to featured material in each subspecialty through AATS Journals Alerts, a monthly email containing featured in-press articles for adult cardiac, congenital, or thoracic surgery. Readers can receive all the latest information published in their respective subspecialty through one AATS Journals Alert.

We are excited by the support that AATS members and all our authors and readers have given the new publications. Together, we can provide valuable information to surgeons through a strong, diverse portfolio of AATS publications.

\section{Reference}

1. Weisel R, McGrath S. New developments for AATS publications. J Thorac Cardiovasc Surg. 2019;158:820-1. 